resident's general practitioner, who might or might not be the visiting medical officer.

A study in Leicestershire of levels of dependency in residents $^{4}$ showed that $25 \%$ were in need of nursing care. The residential homes have, indeed, repeated one of the lessons of history and recreated the poor-law infirmaries. All the ingredients have reappeared: lack of assessment on admission, lack of defined medical responsibility, inadequate notes, failure to provide for rehabilitation, lack of diagnostic facilities, and an untrained staff.

When it talks of commissioning research into a "new concept" of nursing homes in the hospital sector, the Government seems unaware that it has already created a whole stock of inadequate local authority nursing homes, full of people requiring nursing care. The major reason that elderly people cannot cope at home is because they are ill. Unless medical responsibility for the care of the elderly in residential homes is properly defined and nursing and rehabilitation staff are provided, the policy of increasing turnover in this sector is doomed to failure. The policy is based on straw in its assumption that the elderly are in need of care because they are old and not because they are ill. Diseases such as osteomalacia lead to inability to cope at home; meals on wheels, a home help, and holiday admissions are not, and never will be, the correct treatment.

However good the home care services, some elderly people will have to be cared for in institutions. Some looked to Government, as in Denmark, to define the basic rights of individuals in need of permanent care to have a single room with a private lavatory, to furnish it with their own possessions, and to be cared for by staff trained to understand and meet their needs. Those who expected that will find themselves disappointed.

\footnotetext{
1 Department of Health and Social Security, Welsh Office, Northern Ireland Office. Growing older. London: HMSO, 1981. (Command Paper 8173.)

2 Central Statistical Office. Social trends 11. London: HMSO, 1981.

${ }^{3}$ Department of Health and Social Security. Social Work Services London Region. Residential care for the elderly in London. London: HMSO, 1979.

${ }^{4}$ Clarke M, Hughes AO, Dodd KJ, et al. The elderly in residential care: patterns of disability. Health Trends 1979;11:17-20.
}

\section{Management of angina and hypothyroidism}

Reports of deaths from myocardial infarction or deterioration of angina in patients recently started on thyroid replacement treatment began to appear in the 1930s. Warnings were published of the dangers of too vigorous treatment of hypothyroidism and of the indiscriminate use of thyroid hormone, particularly in patients with chest pain. ${ }^{1}$ Forty years on, the problem persists: hypothyroidism is not infrequently associated with angina, and if coronary artery disease is present treatment with thyroid hormone, which increases the heart rate and stimulates myocardial contractility and oxygen consumption, will probably result in worsening of cardiac symptoms. This dilemma needs to be re-examined in the light of advances in the investigation and treatment of coronary artery disease and of improved methods of managing thyroid disease.

Hypothyroidism and angina are common conditions and may occur together coincidentally, but there is also a more direct association ${ }^{2}$ and hypothyroidism apparently predisposes to coronary artery disease. One important aspect of management, therefore, is the prevention or early treatment of hypothyroidism, which should be possible with the ready availability of assays of serum thyroxine and thyroid-stimulating hormone (TSH) concentrations. Many cases of hypothyroidism result from treatment with radioiodine, and adequate follow-up programmes should be set up to ensure early detection of hypothyroidism.

In the individual patient with hypothyroidism, determining if true angina is present or not is sometimes difficult. A specific question should be asked about chest pain before treatment is begun. In classic myxoedema chest pain indistinguishable from that of angina may occur, with the electrocardiogram showing non-specific abnormalities equally consistent with myocardial ischaemia. Serum activities of enzymes associated with myocardial infarction are raised and so are concentrations of serum lipids. Occasionally the chest pain disappears with thyroid replacement and the electrocardiogram reverts to normal, ${ }^{3}$ but most patients' pain does not improve. Some patients with coronary artery disease give no history of angina; they, too, are at risk when treatment is started. The message must be one of caution in any patient who is a possible candidate for coronary artery disease.

Thyroid replacement should be with thyroxine (T4). Thyroid extract is no longer used because of its variable potency. Triiodothyronine (T3) alone is rather too short acting, leading to undesirable variations in cardiac output. A small oral dose of T4 (usually $25 \mu \mathrm{g}$ ) should be given daily and a clinical assessment made every two to three weeks, with an electrocardiogram and an assessment of thyroid state by measuring the serum TSH concentration. The dose of T4 can be increased cautiously by $25 \mu \mathrm{g}$ increments to a maximum of $150 \mu \mathrm{g}$ daily unless the severity of angina increases, when the dose will need to be reduced.

Medical treatment of the angina can be started before or simultaneously with T4 administration. Beta-blocking drugs such as propranolol are useful except in the presence of severe bradycardia. In addition to its antianginal action propranolol affects the biologically active thyroid hormone $\mathrm{T} 3$ by inhibiting deiodination of the prohormone T4. ${ }^{4}$ Long-acting nitrates may also be of symptomatic benefit. Occasionally anaemia associated with hypothyroidism may be a contributory factor, when cautious transfusion of red cells may help to alleviate the angina. ${ }^{5}$

Despite these measures, adequate replacement of T4 may be unattainable because of the severity of angina. Many patients have had to accept the unsatisfactory compromise of continuing hypothyroidism, with its attendant ill health, misery, and risk of neuropsychiatric disturbance. ${ }^{5}$ One possible solution is coronary artery surgery. Published data on this procedure in patients with angina and hypothyroidism are scarce. In three series $^{5-7}$ with a total of 32 patients selective coronary angiography showed severe proximal coronary artery disease, and coronary artery bypass grafting was performed in 25 cases. After surgery adequate replacement with T4 was generally achieved. Both angiography and surgery were well tolerated with no mortality and no major surgical complications. Maintenance of the hypothyroid state at the time of surgery was not associated with increased morbidity. These results suggest that in patients with incapacitating angina coronary artery bypass grafting can be considered before correcting the hypothyroidism. More studies are needed to provide data for further analysis. 
${ }^{1}$ Smyth CJ. Angina pectoris and myocardial infarction as complications of myxedema: with especial reference to the danger of treatment with thyroid preparations. Am Heart $\mathcal{f}$ 1938;15:652-60.

2 Steinberg AD. Myxedema and coronary artery disease-a comparative autopsy study. Ann Intern Med 1968;68:338-44.

${ }^{3}$ Keating FR, Parkin TW, Selby JB, Dickinson LS. Treatment of heart disease associated with myxedema. Prog Cardiovasc Dis 1961 ;3:364-81.

- Lotti G, Delitala G, Devilla L, Alagna S, Masala A. Reduction of plasma triiodothyronine (T3) induced by propranolol. Clin Endocrinol (Oxf) 1977;6:405-10.

5 Levine HD. Compromise therapy in the patient with angina pectoris and hypothyroidism. A clinical assessment. $A m \mathcal{F} \mathrm{Med} 1980 ; 69: 411-7$

- Paine TD, Rogers WJ, Baxley WA, Russell RO. Coronary arterial surgery in patients with incapacitating angina pectoris and myxedema. $A m \mathcal{J}$ Cardiol $1977 ; 40: 226-31$.

${ }^{7}$ Hay ID, Duick DS, Maloney JD, Vlietstra RE, Pluth JR. Thyroid hormone therapy in hypothyroid patients undergoing coronary angiography and aortocoronary bypass graft surgery. In: Stockigt JR, Nagataki S, eds. Thyroid research VIII. Canberra: Australian Academy of Science, 1980:526-8.

\section{Adverse drug reactions}

To be accepted as effective and reasonably safe a drug has to pass a series of prolonged and expensive tests. Yet when looking at its adverse effects doctors seem to apply double standards. While one or two unconfirmed case reports may be enough to label a drug as having unusual toxicity, little is known of the incidence of the less spectacular adverse effects of drugs in widespread general use. The monitored release schemes have not been very productive, and the yellow card system is grossly underused by all doctors. ${ }^{1}$

Adverse drug reactions are often classified into two types. Type 1, or type A, effects are those effects to be expected from pharmacological properties of the drug, such as bleeding when taking warfarin or hyperkalaemia with spironolactone. Type 2, or type B, reactions are the unexpected ones, which, while less common than type 1 reactions, usually carry a much higher morbidity and mortality. Rawlins has given more details of this classification in a recent review in the $B M$ F. $^{2}$ Most drug reactions are mild, but a few may be severe enough to threaten life, especially in patients with serious underlying disease. Some years ago in the United States up to 140000 deaths were said to occur each year from adverse reactions to drugs, ${ }^{34}$ and one-seventh of all hospital days were said to be devoted to the care of patients suffering from drug toxicity. ${ }^{5}$ These statements are now seen as exaggerations, but considerable alarm was caused at the time. The trouble was caused partly by lack of definition of an adverse drug reaction. Clear definitions are now accepted which categorise drug reactions as definite, probable, possible, conditional, and doubtful. ${ }^{3}$ Medical journals have helped to minimise unnecessary anxiety by printing reports in only the first two or, at most, three categories.

Using these criteria, comprehensive studies (such as those carried out by the Boston Collaborative Drug Surveillance Program) have shown that among patients admitted to an acute medical ward adverse drug reactions will be seen in $10 \%$ to $15 \%$ of patients ${ }^{6}{ }^{7}$ but that most will be mild and, at worst, only an inconvenience to the patient. Life-threatening reactions among such patients have been reported to occur in $3 \%$ of patients in American hospitals, ${ }^{4}$ but in a combined British and American study Lawson and his colleagues ${ }^{8}$ found only 28 instances of life-threatening reactions among 2580 medical inpatients $(1 \cdot 1 \%)$. These reactions were more common in patients with known cancer, and hyperkalaemia and hypokalaemia were the most common drug-induced reactions. In a further study ${ }^{9}$ Lawson and his colleagues found 73 cases $\underline{T}$ of severe hypokalaemia over a three-year period, with a $\$ particularly high incidence in patients with myeloid leukaemia. $\frac{8}{\varsigma}$ In nearly 27000 carefully monitored patients fewer than one in 1000 were considered to have died as the result of an adverse drug reaction. ${ }^{10}$ Digoxin and cytotoxic agents figured prominently in this series, and six of the 24 deaths might have been preventable.

What about the admission to hospital of patients primarily because of an adverse drug reaction ? In four recent studies ${ }^{11-14}$ the results were consistent, with $2.9 \%, 3.7 \%, 4.1 \%$, and $5 \cdot 7 \%$ of admissions respectively being primarily due to an adverse drug reaction. Admissions to intensive care units might be thought to be a measure of more severe drug reactions, but the data can be misinterpreted. In a study in France $1.8 \%$ of admissions over a 10 -year period were due to drug toxicity. ${ }^{15}$ In another French study Trunet and his colleagues ${ }^{16}$ found that 40 out of 325 admissions to an intensive care unit were due to iatrogenic disease, but this high proportion was probably due to the admission of most patients from surrounding hospitals rather than from the patient's home. Adverse drug reactions are not solely the province of hospital doctors, ${ }^{17}$ and one in 40 of consultations in general practice is due to iatrogenic disease. ${ }^{18}$

Certain groups of patients are at higher-than-average risk of $\dot{\infty}$ developing an adverse drug reaction. These reactions are more common in women than in men, ${ }^{11} 14$ particularly white women rather than black women, ${ }^{11}$ and there is increasing interest in the genetic contribution to adverse drug reactions. ${ }^{19}$ Adverse reactions are more likely in the elderly and in patients given multiple drug treatment. ${ }^{1314}$ The disease itself will also contribute to the likelihood of an adverse drug reaction, drug reactions being more likely in patients with impaired renal function $^{13} 14$ and with cancer. ${ }^{916}$ In most reports certain drugs stand out and we should be particularly careful in their use: these include aspirin, digoxin, diuretics, antibiotics, anticoagulants, and corticosteroids and other immunosuppressive drugs.

In general, severe adverse reactions are uncommon, and the benefits of drug treatment usually outweigh the disadvantages. Nevertheless, most studies show that $25 \%$ of these adverse drug reactions are preventable. ${ }^{101314}$ What can we as prescribing doctors do to prevent these reactions ? Firstly, we must all have a higher index of suspicion. This does not mean rushing into print at the slightest provocation, but thinking that an unusual or unexpected event may be due to drug toxicity. If in doubt, a yellow adverse drug reaction card should be filled in and posted to the Committee on Safety of Medicines. Secondly, we should take particular care in our use of highrisk drugs and in high-risk patients. Finally, local schemes for monitoring adverse drug reactions both in hospitals and in general practice will keep the possibility at the front of our minds. Such a scheme was mooted in these columns two years $\mathrm{ago}^{20}$ and has in general been greeted with masterly inactivity. Perhaps better progress can be made in the next two years.

1 Inman WHW. Detection and investigation of adverse drug reactions. In: Davies DM, ed. Textbook of adverse drug reactions. London: Oxford University Press, 1977:41-53.

${ }^{2}$ Rawlins MD. Adverse drug reactions. Br Med 7 1981 ;282:974-6.

${ }^{3}$ Karch FE, Lasagna L. Adverse drug reactions: a critical review. $\mathfrak{F} A M A$ $1975 ; 234: 1236-41$.

4 Jick H. Drugs-remarkably nontoxic. N Engl f Med 1974 ;291 :824-8.

5 Melmon KL. Preventable drug reactions-causes and cures. $N$ Englf Med 응 $1971 ; 284: 1361-8$.

${ }^{6}$ Hurwitz N, Wade OL. Intensive hospital monitoring of adverse reactions to drugs. Br Med f 1969 ; i :531-6. 